\title{
Template-free synthesis of hybrid silica nanoparticle with functionalized mesostructure for efficient methylene blue removal
}

\author{
Dambarudhar Parida $^{\text {a,*, }}$ Khalifah A. Salmeia a,b ${ }^{\text {abmin Sadeghpour }}{ }^{\text {c,d }}$, Shanyu Zhao ${ }^{\text {e }}$, Anjani K. Maurya ${ }^{\text {c,f }}$, \\ Khaleel I. Assaf ${ }^{\mathrm{b}}$, Eva Moreau ${ }^{\mathrm{a}}$, Robin Pauer ${ }^{\mathrm{g}}$, Sandro Lehner ${ }^{\mathrm{a}}$, Milijana Jovic ${ }^{\mathrm{a}}$, \\ Hirsch Cordula $^{\text {h, Sabyasachi Gaan }}{ }^{\mathrm{a}, *}$ \\ a Laboratory for Advanced Fibers, Empa Swiss Federal Laboratories for Materials Science and Technology, Lerchenfeldstrasse 5, 9014 St. Gallen, Switzerland \\ ${ }^{\mathrm{b}}$ Department of Chemistry, Faculty of Science, Al-Balqa Applied University, 19117 Al-Salt, Jordan \\ c Center for X-Ray Analytics, Empa, Swiss Federal Laboratories for Materials Science and Technology, CH-9014 St. Gallen, Switzerland \\ d Biomaterials Science Center, Department of Biomedical Engineering, University of Basel, 4123 Allschwil, Switzerland \\ e Laboratory for Building Energy Materials and Components, Empa, Swiss Federal Laboratories for Materials Science and Technology, Überlandstrasse 129, Dübendorf CH-8600, Switzerland \\ ${ }^{\mathrm{f}}$ Cellular and Biomedical Sciences, Faculty of Medicine, University of Bern, Bern, Switzerland \\ ${ }^{g}$ Advanced Materials and Surfaces, Empa, Swiss Federal Laboratories for Materials Science and Technology, Dubendorf CH-8600, Switzerland \\ h Particle-Biology Interactions Laboratory, Swiss Federal Laboratories for Materials Science and Technology, Lerchenfeldstrasse 5, CH-9014 St. Gallen, Switzerland
}

\section{H I G H L I G H T S}

- Template free route for hybrid silica nanoparticles with $\sim 500 \quad \mathrm{~m}^{2} \cdot \mathrm{g}^{-1}$ surface area.

- Cocondensation of a nonsilane precursor to achieve phosphonic acid functionality.

- Silica nanoparticles displayed high Methylene blue adsorption $(380 \mathrm{mg}$. $\left.\mathrm{g}^{-1}\right)$.

- This method broaden the precursor selection for mesoporous silica synthesis.

\section{A R T I C L E I N F O}

\section{Article history:}

Received 18 November 2020

Received in revised form 12 January 2021

Accepted 13 January 2021

Available online 18 January 2021

\section{Keywords:}

Hybrid silica

Mesoporous silica nanoparticles

Co-condensation

Phosphonic acid

Methylene blue adsorption

\section{G R A P H I C A L A B S T R A C T}

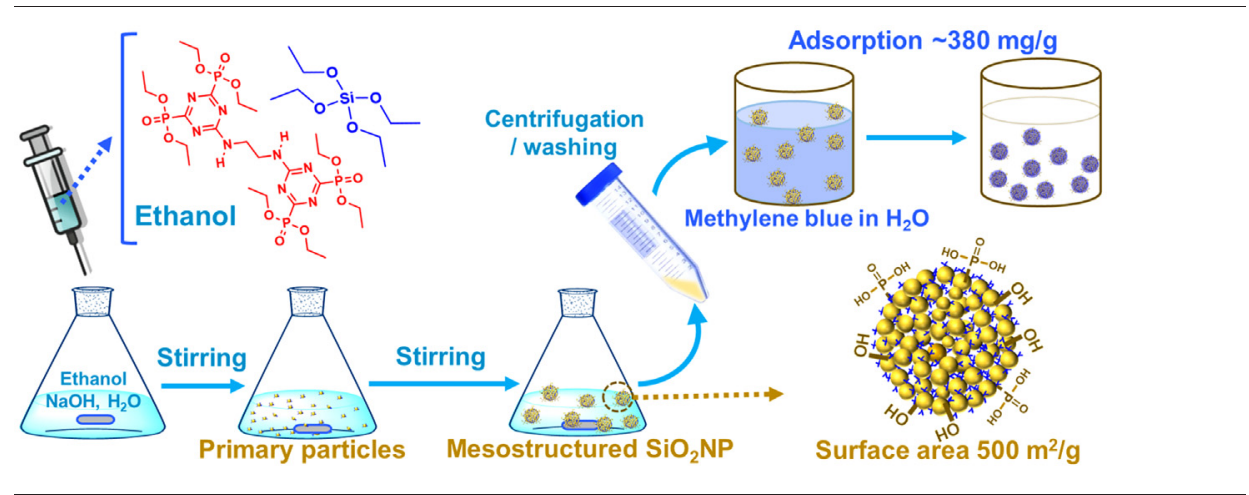

\begin{abstract}
A B S T R A C T
A simple one-pot synthesis process for functionalized mesostructured silica nanoparticles (MSNP) is reported. The novel process demonstrated the possibility to achieve MSNP with a surface area up to $501 \mathrm{~m}^{2} \cdot \mathrm{g}^{-1}$ using a phosphonate based nonsilane precursor such as $\mathrm{N} \mathrm{N}^{\prime}$-bis[4,6-bis(diethylphosphono)-1,3,5-triazin-yl]-1,2diaminoethane (ED). MSNP obtained by using $20 \mathrm{~mol} \%$ of ED achieved a surface area of $80 \mathrm{~m}^{2} \cdot \mathrm{g}^{-1}$ and increasing the ED content to $30 \mathrm{~mol} \%$ resulted in a surface area of $501 \mathrm{~m}^{2} . \mathrm{g}^{-1}$. Zeta potential of novel MSNPs $(-65.5$ and $70.0 \mathrm{mV}$ ) were much higher than the nanoparticle (NP) prepared from only TEOS ( $-49 \mathrm{mV})$, indicating the presence of a large number of $-\mathrm{SiOH}$ and phosphonic acid surface functional groups, as confirmed by Fourier-transform infrared spectroscopy (FT-IR) and Nuclear magnetic resonance (NMR) analysis. The functionalized MSNPs were used as an adsorbent for the removal of cationic pollutants like methylene blue (MB). The MSNP with the highest porosity displayed favorable MB adsorption behavior with $380 \mathrm{mg} \cdot \mathrm{g}^{-1}$ of MB adsorption capacity. Facile regeneration in an acidic medium ( $\sim \mathrm{pH} 4.5)$ with easy recyclability (10 cycles) confirmed the practical applicability of this novel functionalized MSNPs.
\end{abstract}

(c) 2021 The Author(s). Published by Elsevier Ltd. This is an open access article under the CC BY license (http:// creativecommons.org/licenses/by/4.0/).

\footnotetext{
* Corresponding authors.

E-mail addresses: dambarudhar.parida@empa.ch (D. Parida), sabyasachi.gaan@empa.ch (S. Gaan).
} 


\section{Introduction}

Degradation-resistant dyes present in industrial effluents accumulate in water bodies and have the potential to cause irreversible damage to aquatic ecosystems and also pose a serious threat to human health. For example, high doses of accumulated methylene blue (MB) in water can cause anemia, breathing difficulties, and nausea [1]. Removing these pollutants from water by adsorption is a viable and safer option of pollution control, unlike oxidation or degradation methods, where degradation product of these dyes can lead to secondary pollution. Thus, several adsorbents have been designed for efficient removal of the MB and similar cationic pollutants [2-9]. The use of functionalized hydrogels [3,4], carbon-based adsorbents [5], and mesoporous silica nanoparticles (MSNs) $[6,7,10]$ are extensively investigated because of their high adsorption capacity. Recently adsorbents designed from agricultural wastes have gained interest due to their low cost, although their low adsorption capacity makes them unattractive for commercial exploitation [11,12]. Among adsorbents, MSNs have attracted a lot of attention, owing to their docile nature, high stability, and potential applications in the field of drug delivery $[13,14]$, bio-molecule delivery [15,16], bioimaging [15], and many more areas [17-20].

Even though MSNs are promising candidates in many fields, their preparation is mainly template-directed methods of silane precursors followed by template removal to achieve porosity [21-23]. Ideally, detemplating should ensure unblocked pores with a large number of silanol (-SiOH) groups. Calcination is considered an effective method of detemplatation to achieve the final porosity. However, high temperature $\left(500-600{ }^{\circ} \mathrm{C}\right)$ during calcination leads to the destruction of $-\mathrm{SiOH}$ groups due to thermal condensation and resulting in an inert mesoporous surface [24]. Besides, calcination can result in structural shrinkage, agglomeration, and loss in porosity. To avoid agglomeration and maintain the surface -SiOH groups, detemplatation via dissolution using an organic solvent [25] or supercritical fluid [26] is followed. The use of relatively lower temperature in the dissolution method makes it more suitable for synthsis of co-condensed MSNs with organic functionalities. However, complete removal of templates by dissolution is quite challenging and can take several days [27].

Only a few templateless synthesis methods are reported in the literature for preparation of MSNs. In one such method, nano aggregate of poly(N-isopropylacrylamide) (PNIPAm) above its LCST temperature was used as a template for condensation of TEOS [28]. Later, lowering the temperature below LCST made PNIPAm water-soluble and was easily removed from the silica nanoparticles to achieve porosity. MSN obtained by this method displayed low porosity $\left(245 \mathrm{~m}^{2} \cdot \mathrm{g}^{-1}\right)$ and the method was found to be unsuccessful in presence of thermoresponsive polymers like poly(vinyl methyl ether). On the other hand, reported template-free methods produced aggregated mesoporous silica with high porosity ( $537 \mathrm{mg}^{-g^{-1}}$ ) [29]. Though both these methods are template free, low porosity [28] and morphoplogy (aggregated) of the material produced [29] ultimately limit their application.

To address aforementioned challenges, this work reports a singlestep template free route for preparation of functionalized mesostructured silica nanoparticles (MSNPs) via co-condensation of tetraethyl orthosilicate (TEOS) and a non-silane precursor like $\mathrm{N}^{\mathrm{N}} \mathrm{N}^{\prime}$-bis [4,6-bis(diethylphosphono)-1,3,5-triazin-yl]-1,2-diaminoethane (ED, Fig. 1b) [30]. Phosphonate groups in ED prevent a sudden change in $\mathrm{pH}$ of the reaction medium. Upon hydrolysis of phosphonate groups under strong alkaline conditions generates multiple phosphonic acid groups (Fig. S3c) which increases the possibility of ED-TEOS cocondensation to form Si-O-P hybrid networks and eventually MSNPs. Formation of MSNPs was confirmed by Electron microscopy, nitrogen adsorption, and Small-angle X-ray scattering (SAXS) analysis. The inclusion of ED in Si-O-Si network and generation of functional mesostructured surface with silanol $(-\mathrm{SiOH})$ and phosphonic acid functionalities was confirmed by nuclear magnetic resonance (NMR) and fourier-transform infrared spectroscopy (FT-IR). Then, decontamination of water by removing cationic pollutants like methylene blue was demonstrated using MSNP as an adsorbent. Apart from pollution control, phosphonic acid functionalized MSNs are used as proton exchange membranes [31,32], active bio-molecule carrier systems [33]. Additionally, materials containing silica and phosphorous hybrid are kown for their impoved flame ratardancy [34-36].

\section{Materials and methods}

\subsection{Materials}

TEOS (99\%), NaOH, ethanol (99.8\%), diethyl ether (99\%), MB, Congo Red (CR), and Brilliant Blue were purchased from Sigma-Aldrich and used as received. N,N'-Bis[4,6-bis(diethylphosphono)-1,3,5-triazin-yl]1,2-diaminoethane (ED) was synthesized following the procedure given in supplementary information (SI, Fig. S1) [30]. Preliminary in vitro cytotoxicity assessment indicates that ED does not pose a risk for human cells (see Sec. S1.3 for detail). (a)

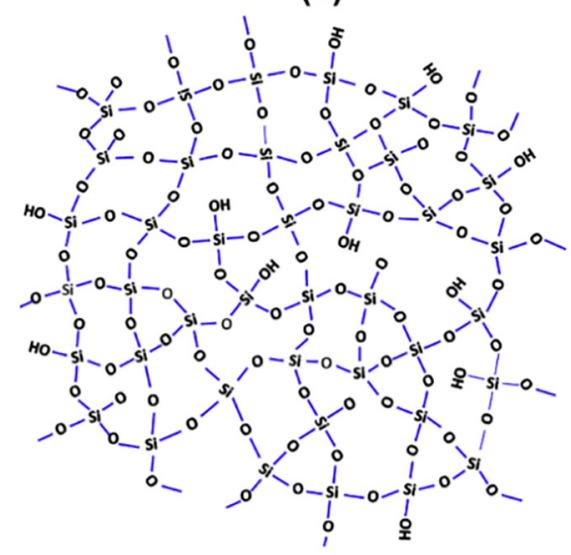

Condensation of TEOS (b)

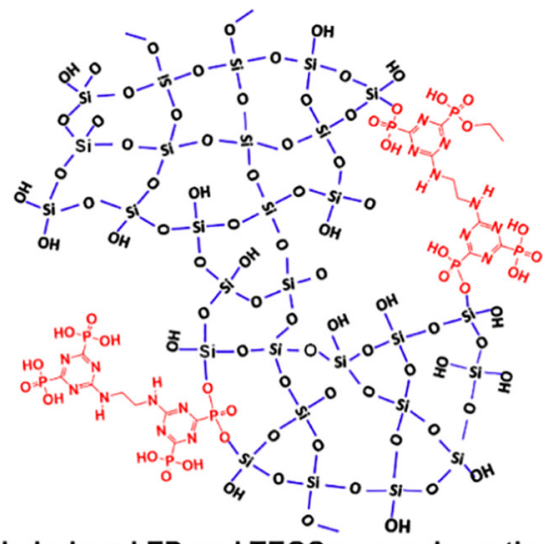

Hydrolyzed ED and TEOS co-condensation (c)

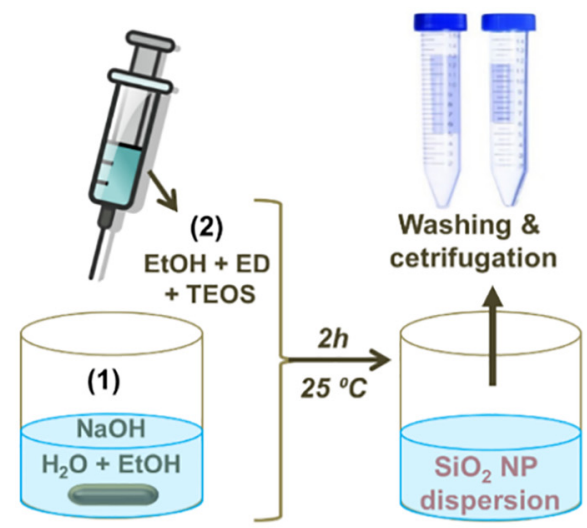

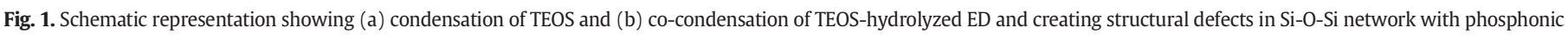
acid functionality. (c) Procedure for silica nanoparticle synthesis using different loading of ED. 


\subsection{Synthesis of silica NPs}

Silica NPs were synthesized following a modified reported protocol $[37,38]$ using TEOS and ED as precursors (Fig. 1c, Table 1). Typically, a freshly prepared solution of ED and TEOS in $6 \mathrm{~mL}$ of ethanol was added dropwise for $1 \mathrm{~min}$ to an $\mathrm{H}_{2} \mathrm{O}$-ethanol mixture (54 mL, 1.25:1) with the required quantity of $\mathrm{NaOH}$ (at $25^{\circ} \mathrm{C}$ and $800 \mathrm{rpm}$ ). After $2 \mathrm{~h}$ of reaction time, $40 \mathrm{~mL}$ of diethyl ether was added to the mixture under stirring and centrifuged for $10 \mathrm{~min}$ at $7000 \mathrm{rpm}$ to isolate NPs. $15 \mathrm{~mL}$ of ethanol- $\mathrm{H}_{2} \mathrm{O}$ mixture was added to the collected particles and samples were sonicated for 15 min and stirred for 30 more minutes. Then, MSNPs were recovered by centrifugation and washing in ethanol$\mathrm{H}_{2} \mathrm{O}$ mixture was repeated four times to ensure removal of unreacted precursors. Finally, collected NPs were dried under vacuum at $75{ }^{\circ} \mathrm{C}$ for $48 \mathrm{~h}$.

\subsection{Characterization}

NMR spectra of ED and hydrolyzed ED were recorded on a Bruker Advance III 400 NMR spectrometer (Sec. S1.2). For Solid-state ${ }^{31} \mathrm{P} \mathrm{CP}$ MAS NMR analysis, a $4 \mathrm{~mm}$ CP-MAS probe with $4 \mathrm{~mm}$ zirconia rotor was used. ${ }^{31} \mathrm{P}$ CP-MAS NMR spectra were recorded at $162.0 \mathrm{MHz}$ using $3.5 \mu \mathrm{s} 90^{\circ}$ excitation pulse on $1 \mathrm{H}$ channel and $2 \mathrm{~ms}$ contact time. Resonance of solid $\mathrm{NH}_{4} \mathrm{H}_{2} \mathrm{PO}_{4}(0.0 \mathrm{ppm})$ was used as reference and calculation was performed by Gaussian 09 software. The geometries were optimized at the B3LYP level using a 6-31 + G* basis set in gas phase. Chemical shifts were calculated by GIAO method and values are reported relative to $\mathrm{H}_{3} \mathrm{PO}_{4}(0.00 \mathrm{ppm})$.

FT-IR spectra were recorded in a Bruker FT-IR (Tensor 27, Switzerland), under transmission mode using MSN-KBr pallets and analyzing by OPUS ${ }^{\mathrm{TM}} 7.2$ software.

Scanning electron microscopic (SEM) images were recorded on a Hitachi S-4800 SEM operating at $20 \mathrm{kV}$. Before SEM analysis, NP dispersion in ethanol was casted on a silicon wafer and dried for $4 \mathrm{~h}$ under the atmospheric condition, and coated with $7 \mathrm{~nm} \mathrm{Au} / \mathrm{Pd}$ coating.

TEM analysis was carried out in TEM, JEOL JEM2200fs microscope operating at $200 \mathrm{kV}$. For TEM analysis, the sample was prepared by putting a drop of NP dispersion ( $0.5 \mathrm{mg}$ in $1 \mathrm{~mL}$ ethanol) on a Lacey carbon copper TEM grid and dried overnight under atmospheric conditions.

$\zeta$-potentials of NPs dispersed in water ( $\mathrm{pH} \mathrm{7,} \mathrm{sonicated} 2 \mathrm{~min}$ ) was measured at $25^{\circ} \mathrm{C}$ by a Malvern Zetasizer ZS equipment using DTS 1070 folded capillary cells.

$\mathbf{N}_{\mathbf{2}}$ adsorption and desorption isotherms were recorded at $77 \mathrm{~K}$ on a TriFlex $\mathrm{N}_{2}$ sorption analyzer (Micromeritics, US) with $15 \mathrm{~s}$ equilibration after degassing for $20 \mathrm{~h}$ at $75^{\circ} \mathrm{C}$ and 1.33 mbar. The specific surface areas (SBET, uncertainty $\sim 20 \mathrm{~m}^{2} \cdot \mathrm{g}^{-1}$ ) were obtained by using Brunauer-Emmett-Teller (BET) method [39], and the pore volume $\left(\mathrm{V}_{\mathrm{BJH}}\right)$ and average pore size $\left(\mathrm{D}_{\mathrm{BJH}}\right)$ was estimated via Barrett-JoynerHalender (BJH) model [40].

Small-angle X-ray scattering (SAXS) analyses were performed on a Nanostar (Bruker AXS GmbH) with a 2D Xe-based gaseous avalanche detector (VÅNTEC-2000). A micro-focused Cu-K $\alpha$ X-ray $(\lambda=$ $0.154 \mathrm{~nm}$ ) with Möntel optics and two-pinhole collimation provided a beam diameter of $\sim 400 \mu \mathrm{m}$. A resolvable scattering vector of 0.09-3.2 $\mathrm{nm}^{-1}$ was achieved at $67 \mathrm{~cm}$ sample-detector distance and the transmission signal recorded with the help of a homemade

Table 1

TEOS, ED, and $\mathrm{NaOH}$ used for the preparation of silica nanoparticles.

\begin{tabular}{llllll}
\hline Entry & TEOS $(\mathrm{g})$ & ED $(\mathrm{g})$ & ED/TEOS molar ratio & $\mathrm{NaOH}(\mathrm{mg})$ & Sample name \\
\hline 1 & 1.12 & 0 & 0 & 42 & $0 \mathrm{SiO}_{2}$ \\
2 & 1.12 & 0.82 & 0.2 & $42,60,72,78$ & $1 \mathrm{SiO}_{2}$ \\
3 & 1.12 & 1.23 & 0.3 & $90,105,110$ & $2 \mathrm{SiO}_{2}$ \\
4 & 1.12 & 1.64 & 0.4 & $110,117,125$ & $3 \mathrm{SiO}_{2}$ \\
\hline
\end{tabular}

beam-stop was used for background subtraction. Quartz capillaries ( $\varnothing$ $1.5 \mathrm{~mm}, \sim 10 \mu \mathrm{m}$ wall, Hilgenberg $\mathrm{GmbH}$, Germany) with NPs were placed in the sample chamber under $\sim 10^{-2}$ mbar vacuum to reduce the scattering due to air, and Silver behenate was used for calibration. 1D radial profiles were extracted from DIFRACEVA software (Bruker AXS, Germany). The scattering patterns were simulated using a model with the Porod function and the Guinier approximation. The former simulates the scattering from large polydisperse NPs $(\geq 100 \mathrm{~nm})$ while the latter takes into account the scattering from small particles (herein the pores). The total scattering function is given in Eq. (1), where, $a, R$, and $b$ are the Porod slope, radius of gyration of the pores, and a background correction constant respectively.

$\mathrm{I}(\mathrm{q})=\frac{1}{\mathrm{q}^{\mathrm{a}}}+\exp \left(\frac{-\mathrm{q}^{2} R^{2}}{3}\right)+b$

Elemental analysis of the nanoparticles was done using the inductively coupled plasma optical emission spectrometry (ICP-OES), on a 5110 ICP-OES apparatus (Agilent Switzerland AG, Basel). Prior to analysis, $15 \mathrm{mg}$ of NPs were dissolved in $3 \mathrm{~mL} \mathrm{HNO}_{3}$ using a microwave.

MB adsorption was carried out by putting $30 \mathrm{mg}$ of MSNPs in $3 \mathrm{~mL}$ MB solutions (200 rpm, $25^{\circ} \mathrm{C}, \mathrm{pH} 7$ ) and stirring for desired time. Then, MSNPs were isolated by centrifugation (7500 rpm, $1 \mathrm{~min}$ ) and UV-vis intensity of residual MB (at $665 \mathrm{~nm}$ ) was recorded by a Cary 50 BIO UV-vis spectrophotometer after required dilution. Concentration of MB was determined by using the MB calibration curve (Fig. S12) and adsorption characteristics were studied by Langmuir [41] and Freundlich isotherms [42]. For MB release study, MB containing NPs ( $5 \mathrm{mg}$ ) were dispersed in $25 \mathrm{~mL}$ of water $\left(200 \mathrm{rpm}\right.$, at $25^{\circ} \mathrm{C}$ ) and $\mathrm{MB}$ release was monitored using a UV-vis spectrophotometer.

\section{Result and discussion}

Solid silica NPs synthesized from TEOS (1.12 g, $90 \mathrm{mmol} / \mathrm{L}$ ) and $\mathrm{NaOH}$ (42 mg, $18.0 \mathrm{mmol} / \mathrm{L}$ ) achieved a uniform size of $401 \pm 21 \mathrm{~nm}$ $\left(\mathbf{O S i O}_{2}\right.$, Fig. 2a) [37,38]. On the contrary, no NPs wereformed at the same $\mathrm{NaOH}$ concentration in presence of $\mathrm{ED}(20.0 \mathrm{~mol} \%)$. It can be attributed to the rapid decrease in $\mathrm{pH}$ of the medium (Fig. S10) due to the formation of phosphonic acid groups after hydrolysis of ED. Following which, a higher concentration of $\mathrm{NaOH}$ was used (Table 1) and the yield of NPs ( $\mathbf{1 S i O}_{\mathbf{2}}$ ) increased (Table S1). At $72 \mathrm{mg}$ of $\mathrm{NaOH}$ in $60 \mathrm{~mL}$ of the mixture, $\mathbf{1 S i O}_{\mathbf{2}} \mathrm{NPs}$ with rough surfaces were formed (Fig. $2 \mathrm{~b}$, $\mathrm{S} 5 \mathrm{~b})$. Further increasing the $\mathrm{NaOH}$ concentration resulted in an extensive cluster formation with a decrease in the surface roughness (Fig. S5c).

With the increase in the ED loading to $30 \mathrm{~mol} \%$, a higher $\mathrm{NaOH}$ concentration was required for synthesis of NP. $105 \mathrm{mg}$ of $\mathrm{NaOH}$ in $60 \mathrm{~mL}$ of ethanol- $\mathrm{H}_{2} \mathrm{O}$ mixture achieved cluster free NPs with rough surface $\left(\mathbf{2 S i O}_{2}\right.$, Fig. $2 \mathrm{c}$ and Fig. S6a, b). Increasing the $\mathrm{NaOH}$ concentration further, clusters with decreased surface roughness were obtained. Additionally, on increasing the ED loading to $40 \mathrm{~mol} \%\left(\mathbf{3 S i O}_{\mathbf{2}}\right)$, very small NPs (Fig. S7a) and two different particle population (Fig. S7b) with a very low yield were obtained (Table S1). An attempt to improve the yield by increasing $\mathrm{NaOH}$ concentration (125 mg, Table 1) led to cluster formation (Fig. S7). It is clear from these observations that at higher $\mathrm{NaOH}$ concentration, TEOS condensation is faster than ED-TEOS cocondensation. This leads to clusters formation with a smoother surface resembling $\mathbf{O S i O}_{2}$. Small particle size of $\mathbf{S S i O}_{2}$ can be challenge for recovery and reuse. Additionally, uncontrolled particle growth and low yield of $\mathbf{3 S i O}_{\mathbf{2}}$ can limit its applictions. Therefore, $\mathbf{3 S i O}_{\mathbf{2}}$ was not considered for further study. 

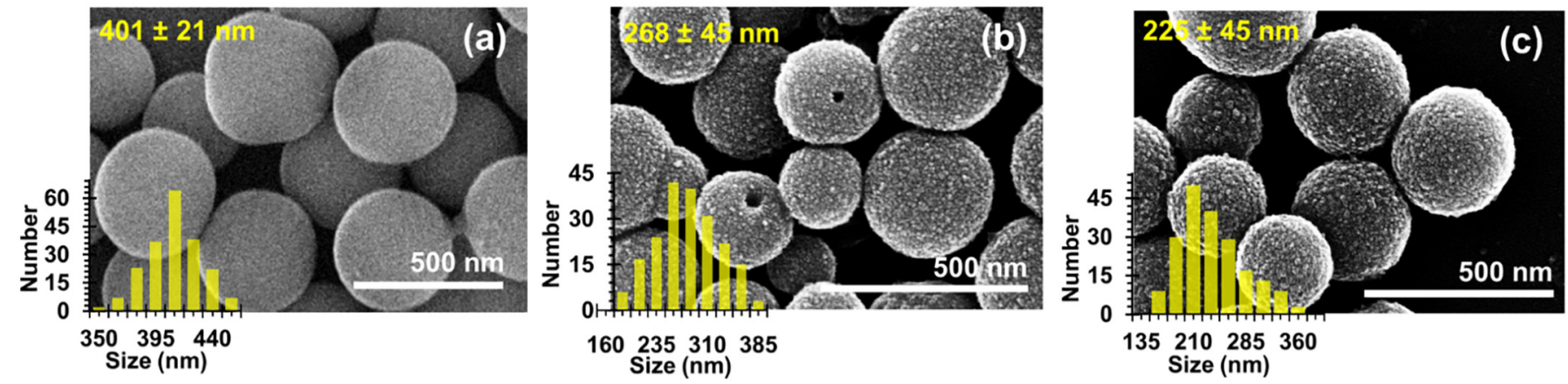

Fig. 2. SEM image and size histogram of (a) $\mathbf{0} \mathbf{S i O}_{2}$, (b) $\mathbf{1} \mathbf{S i O}_{\mathbf{2}}$ and (c) $\mathbf{2} \mathbf{S i O}_{\mathbf{2}} \mathrm{NPs}$.

\subsection{Physical characterization of nanoparticles}

Although the condition mentioned in entry $2(72 \mathrm{mg} \mathrm{NaOH})$ and entry 3 ( $105 \mathrm{mg} \mathrm{NaOH}$ ) of Table 1 achieved the highest quantity of cluster free silica NPs, the overall yield remains lower than $\mathbf{O S i O}_{\mathbf{2}}$ (Table S1). $\sim 9 \%$ of $\mathbf{1 S i O}_{\mathbf{2}}$ NPs have a hole in the center (Fig. $2 \mathrm{~b}$ ) and no such particles were formed in the case of $\mathbf{2} \mathbf{S i O}_{\mathbf{2}}$ (Fig. 2c). The average size of NPs decreased with an increase in the concentration of ED (Fig. S6d). TEM analysis of $\mathbf{1 S i O}_{\mathbf{2}}$ revealed the presence of a darker core and lighter shell of few nanometers (Fig. 3a), indicating a denser core. On the other hand, the TEM image of $\mathbf{2 S i O}_{\mathbf{2}}$ was uniform without any sign of density change within NPs (Fig. 3b).

$\mathrm{N}_{2}$ sorption measurements of the $\mathbf{0 S i O}_{2}$ showed a type II isotherm without hysteresis, and a low surface area of $22 \mathrm{~m}^{2} \cdot \mathrm{g}^{-1}$, indicating its nonporous nature (Fig. $3 \mathrm{c}$ ). $\mathbf{1} \mathbf{S i O}_{\mathbf{2}}$ showed a type IV isotherm with $\mathrm{H} 4$ hysteresis, highlighting the presence of both meso- and micro-pores (pore width $\sim 5.5 \mathrm{~nm}$ ) with a surface area and BJH pore volume of 80 $\mathrm{m}^{2} . \mathrm{g}^{-1}$ and $0.13 \mathrm{~cm}^{3} . \mathrm{g}^{-1}$ respectively (Fig. $3 \mathrm{~d}, \mathrm{~S} 8 \mathrm{a}$ ). In $\mathbf{2} \mathbf{S i O}_{2}$, significant improvement in porosity and a type IV isotherm with $\mathrm{H} 1$ hysteresis was observed (Fig. 3e), indicating a homogeneous mesoporous structure (pore size $\sim 7 \mathrm{~nm}$, Fig. S8). $\mathbf{2 S i O}_{2}$ also displayed a high surface area of $501 \mathrm{~m}^{2} \cdot \mathrm{g}^{-1}$ and BJH volume of $0.74 \mathrm{~cm}^{3} \cdot \mathrm{g}^{-1}$ (Table 2).

Unlike template-directed MSNs [43,44], no pore boundaries were observed during TEM analysis of $\mathbf{2 S i O}_{\mathbf{2}}$ despite high porosity $\left(501 \mathrm{~m}^{2}\right.$. $\mathrm{g}^{-1}$ ), indicating a random pore orientation. SEM analysis of ballmilled $\mathbf{2 S i O}_{2}$ confirmed the presence of randomly interconnected pores formed due to aggregation of nano-domains of $\sim 6 \mathrm{~nm}$ (Fig. S9) and similar observation can also be found in the literature [28]. In SEM image of ball-milled $\mathbf{1 S i O}_{2}$, flaking-off of the porous layer from the top exposed a denser core (Fig. S9a), which is in agreement with the TEM analysis (Fig. 3a).

To confirm the role of ED on the porosity of MSNPs, SAXS experiments were carried out. The $\mathbf{O S i O}_{\mathbf{2}}$ demonstrated a decay in the intensity over q-range of $0.09 \mathrm{~nm}^{-1}$ and $0.5 \mathrm{~nm}^{-1}$ (Fig. 4a). This decay is simulated using the only first part of the Eq. (1) $\left(1 / q^{a}\right)$ to deduce the Porod exponent. Porod decay rate of nearly -4 indicates a smooth surface of $\mathbf{O S i O}_{2}$. The increase in surface roughness leads to high fluctuations in lateral electron density profiles and deviates from the decay
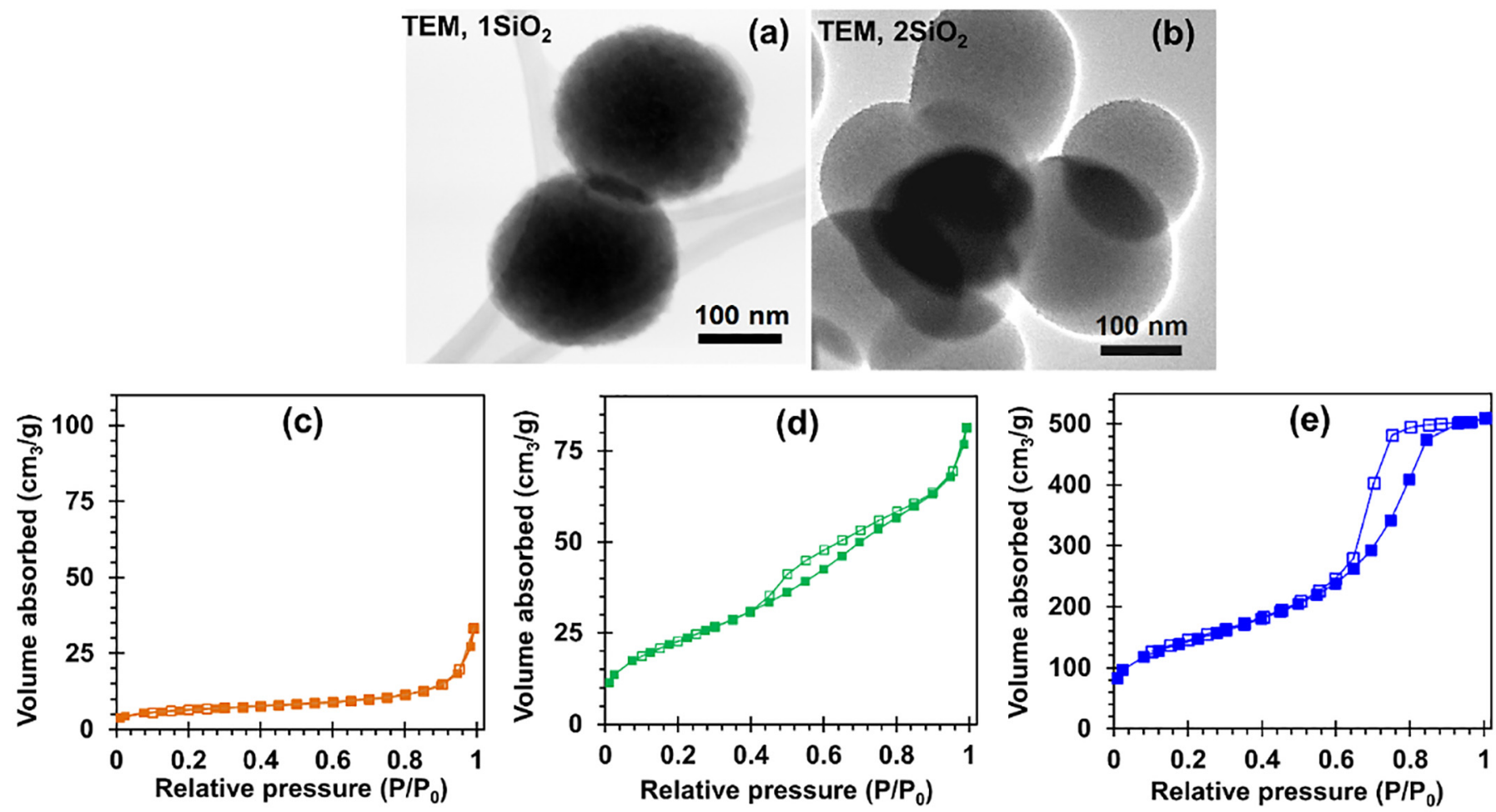

Fig. 3. TEM image of (a) $\mathbf{1 S i O}_{\mathbf{2}}$ and (b) $\mathbf{2 S i O}_{\mathbf{2}}$. $\mathrm{N}_{2}$ adsorption-desorption isotherm of (c) $\mathbf{0} \mathbf{S i O}_{\mathbf{2}}$, (d) $\mathbf{1 S i O}_{\mathbf{2}}$ and (e) $\mathbf{2} \mathbf{S i O}_{\mathbf{2}}$. 
Table 2

Composition and properties of silica NPs synthesized.

\begin{tabular}{lllllll}
\hline Sample & $\begin{array}{l}\text { BET } \\
\text { area } \\
\left(\mathrm{m}^{2} \cdot \mathrm{g}^{-1}\right)\end{array}$ & $\begin{array}{l}\text { Pore } \\
\text { volume } \\
\left(\mathrm{cm}^{3} .\right. \\
\left.\mathrm{g}^{-1}\right)\end{array}$ & $\begin{array}{l}\text { BET } \\
\text { pore } \\
\text { size } \\
(\mathrm{nm})\end{array}$ & $\begin{array}{l}\text { SAXS } \\
\text { pore } \\
\text { size } \\
(\mathrm{nm})\end{array}$ & $\begin{array}{l}{ }^{\text {aP }} \text {-content } \\
(\%)\end{array}$ & $\begin{array}{l}\zeta \text {-potential } \\
(\mathrm{mV})\end{array}$ \\
\hline $0 \mathrm{SiO}_{2}$ & 22 & 0.05 & - & - & - & -49.0 \\
$1 \mathrm{SiO}_{2}$ & 81 & 0.13 & 5.5 & 2.5 & 0.12 & -65.5 \\
$2 \mathrm{SiO}_{2}$ & 501 & 0.75 & 6.5 & 11.5 & 0.70 & -70.0 \\
\hline
\end{tabular}

${ }^{a}$ Phosphorous content (P-content) determined by ICP-OES analysis.

rate of -4 . For extremely rough surfaces, an exponent close to -3 can be obtained [45]. A decrease in Porod exponent for $\mathbf{1} \mathbf{S i O}_{\mathbf{2}}$ and $\mathbf{2} \mathbf{S i O} \mathbf{}_{\mathbf{2}}$ (Fig. 4) is the signature for higher surface roughness and agrees with SEM observation (Fig. 2). The scattering from $\mathbf{1 S i O}_{\mathbf{2}}$ and $\mathbf{2} \mathbf{S i O} \mathbf{}_{\mathbf{2}}$ displayed a broad hump at a high $\boldsymbol{q}$ region (arrow in Fig. 4b, c), and its intensity increased with the increase in ED concentration. This hump also moved towards lower scattering angles for $\mathbf{2 S i O}_{2}$. These observations indicate the growth of pores size within MSNPs. Pore size determined using the Guinier approximation (Eq. (1), $\left.\exp \left(-q^{2} R^{2} / 3\right)\right)$ was found to be 2.2 and $11.3 \mathrm{~nm}$ for $\mathbf{1 S i O}_{\mathbf{2}}$ and $\mathbf{2} \mathbf{S i O}_{\mathbf{2}}$ respectively (Table 2). This implies that ED influences the surface morphology and porosity. Similar findings have also been reported for other morphogenic agents used in MSN preparation [46].

To confirm the incorporation of ED into NPs, P-content of $\mathbf{1 S i O}_{\mathbf{2}}$ and $\mathbf{2} \mathbf{S i O}_{\mathbf{2}}$ was determined by ICP-OES analysis. P-content in $\mathbf{1} \mathbf{S i \mathbf { O } _ { \mathbf { 2 } }} \mathbf{( 0 . 1 \% )}$ and $2 \mathrm{SiO}_{\mathbf{2}}(0.7 \%)$ are lower than the calculated value of $\sim 13.0$ and $\sim 15.5 \%$ for $\mathbf{1} \mathbf{S i O}_{\mathbf{2}}$ and $\mathbf{2} \mathbf{S i O}_{\mathbf{2}}$ respectively. It can be attributed to the slow co-condensation of ED-TEOS compared to the condensation of only TEOS and partial hydrolysis of Si-O-P link [47]. Although there was a difference in P-content and porosity between $\mathbf{1 S i O}_{\mathbf{2}}$ and $\mathbf{2} \mathbf{S i O}_{\mathbf{2}}$, $\zeta$-potential of both MSNPs were similar $(-65.5$ and $-70.0 \mathrm{mV}$, Fig. 5a) and higher than $\mathbf{O S i O}_{\mathbf{2}}(-49 \mathrm{mV})$, indicating the presence of similar functionality $\left(-\mathrm{SiOH}\right.$ and $\left.-\mathrm{PO}(\mathrm{OH})_{2}\right)$ on both the MSNPs.

\subsection{Chemical characterization of NPS}

As mentioned earlier, P-content and porosity of $\mathbf{1 S i O}_{\mathbf{2}}$ were low as compared to $\mathbf{2} \mathbf{S i O}_{\mathbf{2}}$ (Table 2). Therefore, $\mathbf{1} \mathbf{S i O}_{\mathbf{2}}$ was excluded from further detailed study. In the FT-IR spectra of both $\mathbf{O S i O}_{\mathbf{2}}$ and $\mathbf{2 S i O}_{\mathbf{2}}$ (Fig. 5b), intense bands of Si-O-Si skeleton $\left(1088 \mathrm{~cm}^{-1}\right)$ and $\mathrm{Si}-\mathrm{O}-\mathrm{Si}$ bending vibration $\left(799 \mathrm{~cm}^{-1}\right)$ were observed $[23,48]$. The appearance of a shoulder around $1200 \mathrm{~cm}^{-1}$ in the case of $\mathbf{2 S i O}_{2}$ can be attributed to $\mathrm{P}=\mathrm{O}$ groups $[49,50]$. Moreover, the intensity of the peak for $-\mathrm{SiOH}$ symmetric stretching $\left(961 \mathrm{~cm}^{-1}\right)$ was found to be higher in $\mathbf{2 S i O}_{\mathbf{2}}$ [51]. The increased intensity of the band at $1635 \mathrm{~cm}^{-1}$ can be attributed to the adsorption of $\mathrm{H}_{2} \mathrm{O}$ by $\mathrm{P}=\mathrm{O}$ functionality in $\mathbf{2 S i O}_{\mathbf{2}}$ via $\mathrm{H}$-bonding $[23,48]$. The broad shape of this band can arise due to overlapping of the band at $1635 \mathrm{~cm}^{-1}$ arising from - NH of ED [52,53]. The combined effect of absorbed $\mathrm{H}_{2} \mathrm{O}$ by $\mathrm{P}=\mathrm{O}$ functionality and a higher number of $-\mathrm{SiOH}$ significantly increased the intensity of the band at $3000-3700 \mathrm{~cm}^{-1}[48,54]$. These FT-IR observations highlight the incorporation of ED in the Si-O-Si network.
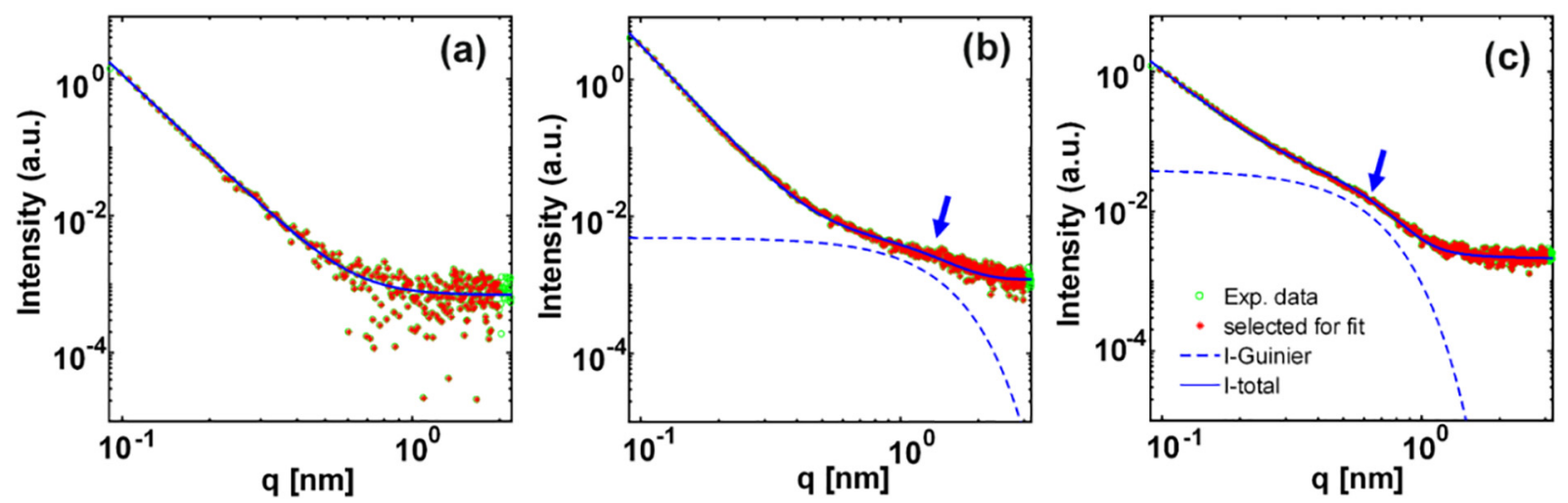

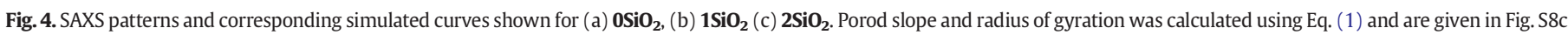
and $\mathrm{d}$.
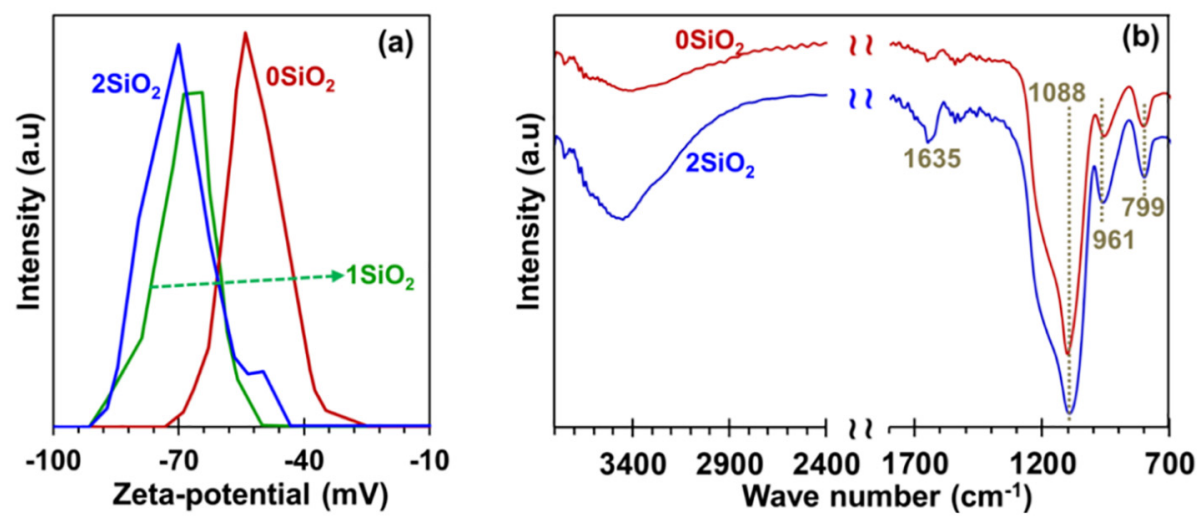

Fig. 5. (a) $\zeta$-potential of $\mathbf{O S i O}_{\mathbf{2}}$ and hybrid MSNPs determined in water at pH 7 and $25^{\circ} \mathrm{C}$. (b) FT-IR spectra of $\mathbf{O S i O}_{\mathbf{2}}$ and $\mathbf{2 S i O}_{\mathbf{2}}$ showing chemical changes after inclusion of ED. 
${ }^{29} \mathrm{Si}$ NMR spectra of both $\mathbf{0 S i O}_{\mathbf{2}}$ and $\mathbf{2 S i O}_{\mathbf{2}}$ showed the presence of $\mathrm{Q}_{4}$ and $Q_{3}$ peak (Fig. 6a) $[55,56]$. However, the intensity of the $Q_{3}$ peak was higher in the case of $\mathbf{2 S i O}_{2}$ along with a new peak of $\mathrm{Q}_{2}$ (Fig. 6a). Higher amount of $\mathrm{Q}_{3}$ and $\mathrm{Q}_{2}$ in $\mathbf{2} \mathbf{S i O}_{2}$ can be due to the disruption in $\mathrm{Si}$-O-Si network during the inclusion of ED. It was difficult to resolve Si-O-P signals that appear between -110 to $-120 \mathrm{ppm}[55,56]$, possibly due to the lower number of Si-O-P links compared to $\mathrm{Q}_{4}$ and $\mathrm{Q}_{3}$.

To get more information, ${ }^{31} \mathrm{P}$ CP-MAS solid NMR spectra (15 and $-10 \mathrm{ppm}$ ) was deconvoluted and six resonances were observed (Fig. 6b). ${ }^{31} \mathrm{P}$ CP-MAS NMR chemical shifts have been simulated using GIAO method according to the change in the chemical environment around the phosphonate groups at each side of the organic precursor (Fig. 6c) [30]. The chemical shift at $4.8 \mathrm{ppm}$ is due to the monodentate binding and at $2.67 \mathrm{ppm}$ is associated with the physiosorption of $-\mathrm{P}(\mathrm{O})(\mathrm{OH})_{2}$ groups with $-\mathrm{SiOH}$. This explains the presence of the $\mathrm{Q}_{2}$ peak in $\mathbf{2 S i O}_{\mathbf{2}}$ compared to $\mathbf{0} \mathbf{S i O}_{\mathbf{2}}$ (Fig. 6a). That's to say, the hydrolysis of the phosphoester forms the phosphonic acid, which can be physiosorbed to the -SiOH group, mitigating the transformation of $\mathrm{Q}_{2}$ to $Q_{3}$ and $Q_{3}$ to $Q_{4}$. The resonance at $11.1 \mathrm{ppm}$ is assigned to the presence of two bidentate bindings on the same side. The resonance at $8.4 \mathrm{ppm}$ can be attributed to bidentate binding of the phosphonate group, which is present next to a physiosorption mode of binding. The NMR resonances between -0.71 to $-5.5 \mathrm{ppm}$ are attributed to the overlapping of physiosorbed $-\mathrm{P}(0) \mathrm{OH}$ on the same side of bonded phosphonate to -SiOH. Unhydrolyzed phosphoester also appears within the same region.

\subsection{Mechanism of MSNP formation}

Based on the different analysis, a simplified mechanism of MSNP formation is proposed in Fig. 7. The presence of very small primary particles (PP) of $\sim 6 \pm 1 \mathrm{~nm}$ size (Fig. S9) observed during SEM analysis were formed in Stage-2, right after the hydrolysis and condensation of precursors in a highly alkaline medium (Stage-1). High alkalinity at Stage- 1 facilitates the hydrolysis and co-condensation of ED with TEOS (Fig. S10). However, incomplete hydrolysis of ED results in the presence of a small fraction of residual phosphoester groups in the final $\mathbf{2} \mathbf{S i O}_{\mathbf{2}}$, which is confirmed by NMR analysis (Fig. 6b) [57]. A higher concentration of ED and $\mathrm{NaOH}$ during the synthesis of $\mathbf{2 S i O}_{\mathbf{2}}$ (Table 1 ) led to a higher ED incorporation in the PPs, which is reflected in the measured P-content of $\mathbf{2 S i O}_{2}$.

The initial stage marked by the rapid decrease in $\mathrm{pH}$ in the case of $\mathbf{1} \mathbf{S i O}_{2}, \mathbf{2} \mathbf{S i O}_{2}$ compared to $\mathbf{0 S i O} \mathbf{}_{\mathbf{2}}$ is attributed to the hydrolysis of phosphoester of ED to phosphonic acid (Fig. S10) and decrease in the co-condensation rate of ED-TEOS. The $\mathrm{pH}$ of the medium remains high enough for TEOS condensation which leads to the formation of secondary particles by aggregation of PPs (Fig. 7) [28,58]. Low ED content in PPs and a higher $\mathrm{pH}$ at Stage- 1 of $\mathbf{1 S i O}_{\mathbf{2}}$ synthesis results in compact secondary particles by incorporation of a higher amount of TEOS (Stage-3). Conversely, a higher amount of ED in PPs and a lower $\mathrm{pH}$ of the medium in the case of $\mathbf{2} \mathbf{S i O}_{2}$ prevented the formation of compact secondary particles. The size of the secondary particles grew via the incorporation of the PPs. However, lowering the $\mathrm{pH}$ due to the formation of phosphonic acid group results in a more open and porous structure (Stage-4). This difference in TEOS condensation in $\mathbf{1 S i O}_{\mathbf{2}}$ synthesis is visible as a denser core during TEM analysis (Fig. 3a). On the contrary, low incorporation of TEOS Stage- 3 and 4 produces porous $\mathbf{2 S i O}_{\mathbf{2}}$ (Fig. 3e). The removal of cocondensed ED due to partial hydrolysis of Si-O-P bond [47] during synthesis also improves the porosity of $\mathbf{2 S i O}_{2}$ to achieve a surface area of $501 \mathrm{~m}^{2} \cdot \mathrm{g}^{-1}$. A lower pH during the synthesis of $\mathbf{2 S i O}_{\mathbf{2}}$ (Fig. S10) reduces the amount of of PPs that can be incorporated, which ultimately decreases the size of $\mathbf{2} \mathrm{SiO}_{\mathbf{2}}$ compared to $\mathbf{1 S i O}_{\mathbf{2}}$ (Fig. 2).

\subsection{Dye removal from water}

High surface area with-SiOH and - $\mathrm{PO}(\mathrm{OH})_{2}$ functionalities make $\mathbf{2} \mathbf{S i O}_{\mathbf{2}}$ an ideal adsorbent. Hence, the adsorption behavior of $\mathbf{2} \mathbf{S i O} \mathbf{2}_{\mathbf{2}}$ was investigated using pollutants like $\mathrm{CR}, \mathrm{BB}$, and $\mathrm{MB}$ (Fig. 8). Equilibrium adsorption of $\mathrm{CR}$ was low (10\%, Fig. S11a), due to competing CR-2SiO and $\mathrm{CR}-\mathrm{H}_{2} \mathrm{O}$ interactions (Fig. S11d). Higher adsorption of $\mathrm{BB}(\sim 38 \%$, Fig. S11b) is the result of slightly stronger $\mathrm{BB}-\mathbf{2 S i O}_{2}$ interaction, owing to more number of amino groups than sulfonic acid groups in BB (Fig. S11e). Nearly complete adsorption of MB within 10 min (Fig. 8c, $\mathrm{S} 11 \mathrm{c})$ is due to the strong interaction between $\mathrm{MB}$ with $-\mathrm{PO}(\mathrm{OH})_{2}$ and -SiOH groups (Fig. S11f).

Considering a fast adsorption of $\mathrm{MB}$ by $\mathbf{2} \mathbf{S i O}_{2}$, detailed adsorption study was carried out (Fig. 8d, e) to predict MB distribution between $\mathrm{H}_{2} \mathrm{O}$ or solid phase $\left(\mathbf{2} \mathrm{SiO}_{2}\right)$ using Langmuir [41] and Freundlich models
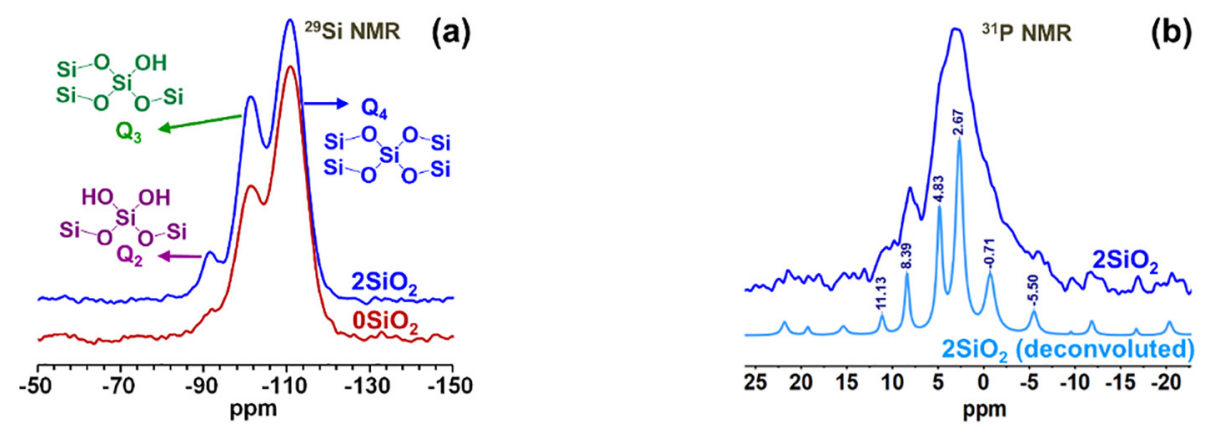

(c)
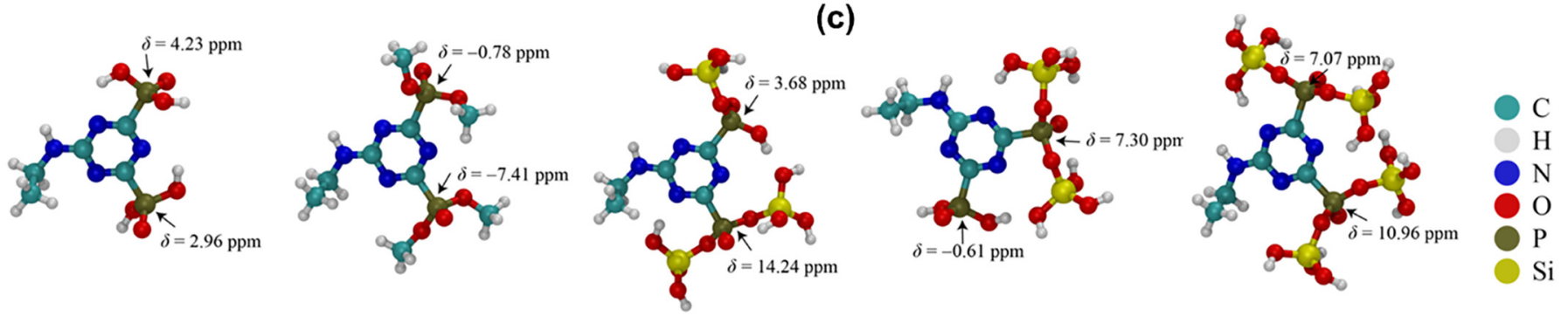

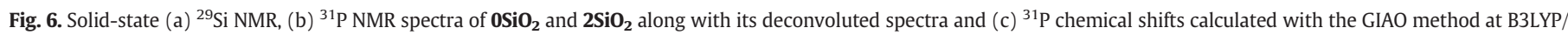
$6-31+\mathrm{G}^{*}$. 


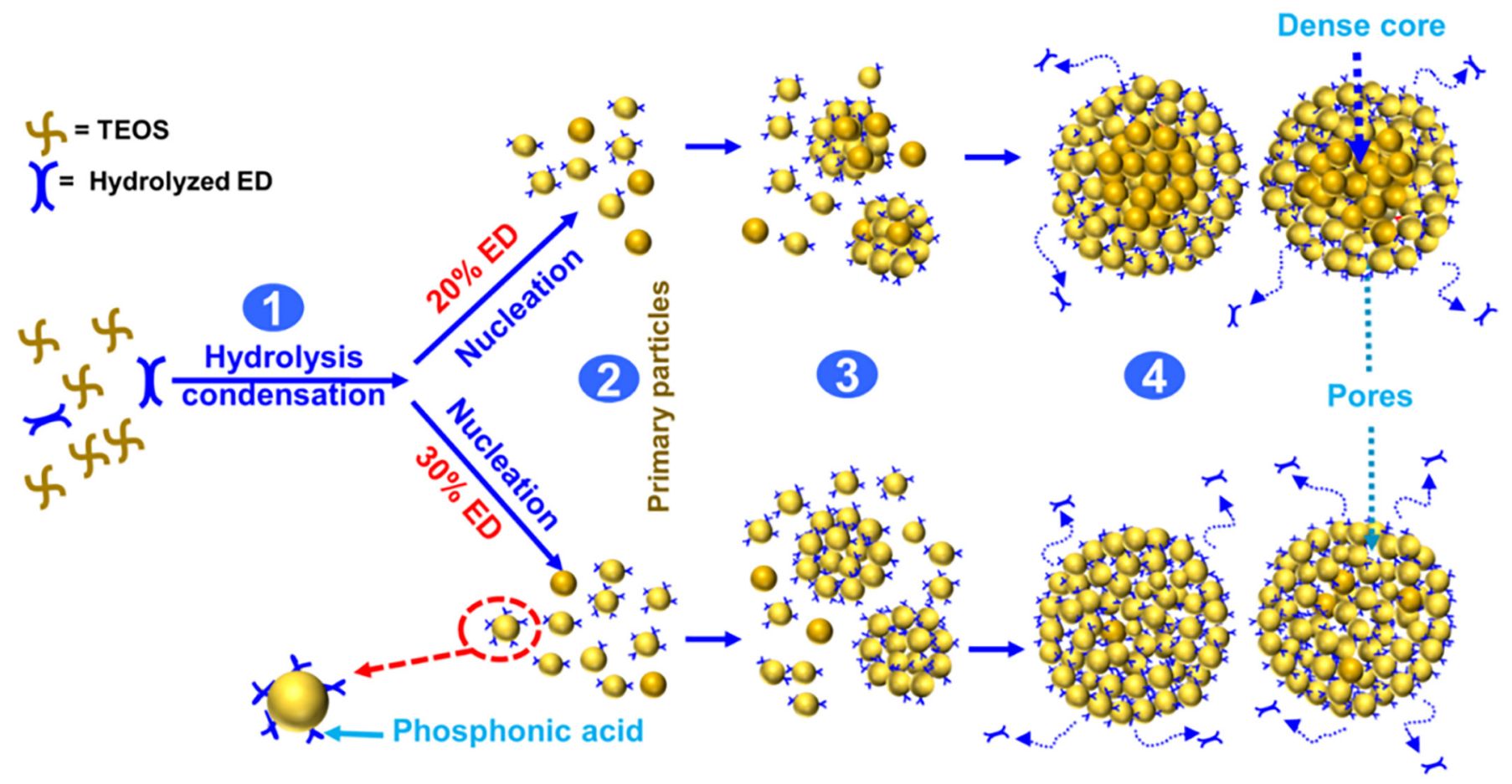

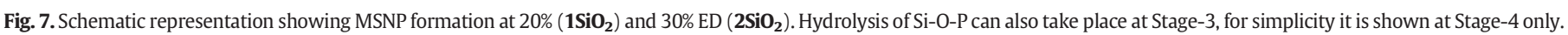
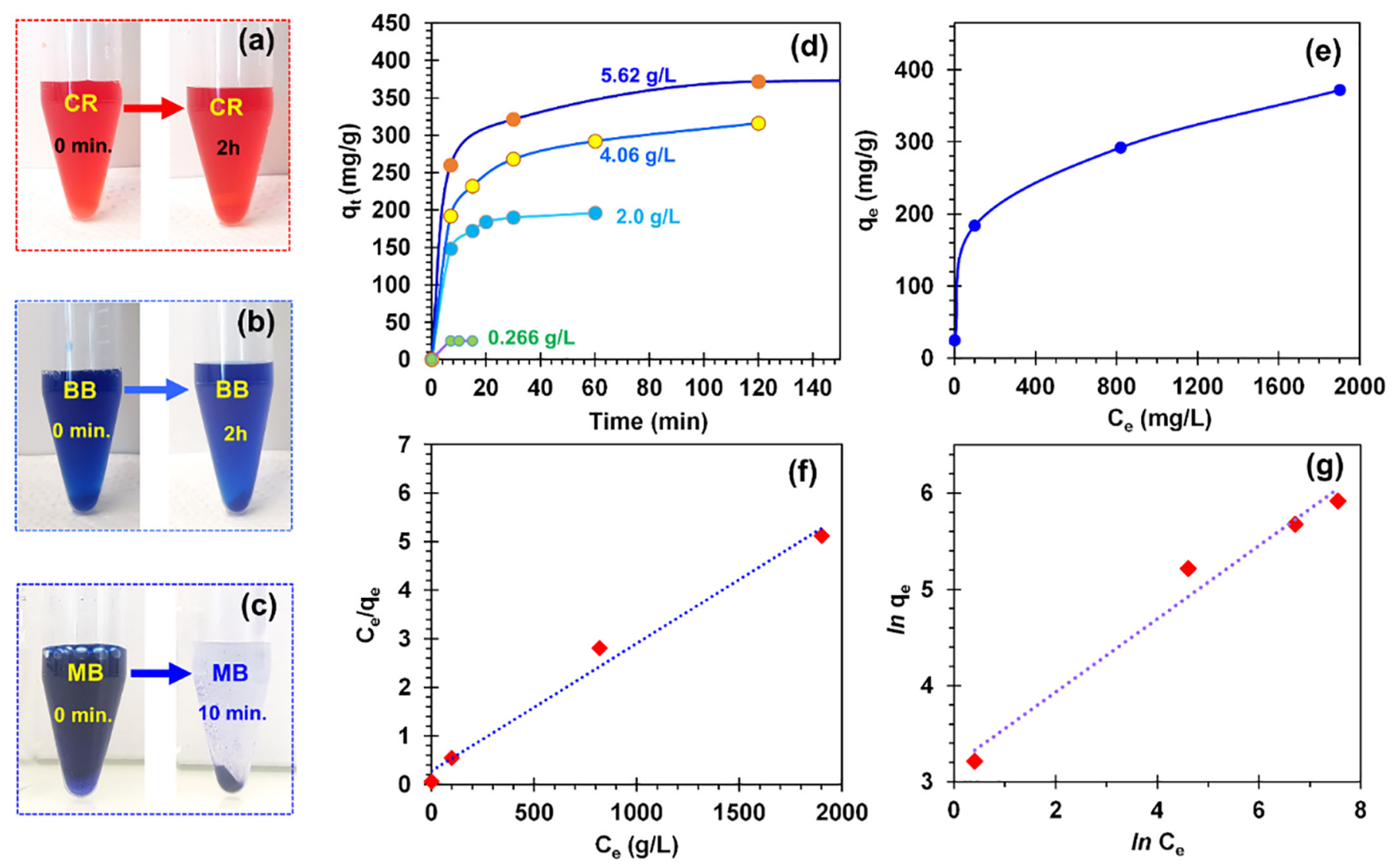

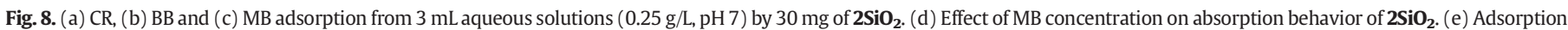
isotherms of MB at equilibrium concentration. (f) Langmuir and (g) Freundlich model of MB absorption by $\mathbf{2 S i O}_{2}$. 
Table 3

Parameters of Langmuir and Freundlich isotherm for MB adsorption by $2 \mathrm{SiO}_{2}$.

\begin{tabular}{lll}
\hline Model & Parameters & Values \\
\hline Langmuir isotherm & $\mathrm{Q}_{\max }\left(\mathrm{mg}^{-1}\right)$ & 380.0 \\
& $\mathrm{~K}_{\mathrm{L}}\left(\mathrm{L}^{-1} \mathrm{~g}^{-1}\right)$ & 0.009 \\
& $\mathrm{R}_{\mathrm{L}}$ & 0.95 \\
\multirow{2}{*}{ Freundlich isotherm } & $\mathrm{R}^{2}$ & 0.99 \\
& $\mathrm{n}$ & 2.56 \\
& $\mathrm{R}^{2}$ & 0.96 \\
\hline
\end{tabular}

[42]. In Langmuir isotherm (Eq. (2)), $C_{e}$ and $q_{e}$ refers to the equilibrium $\mathrm{MB}$ concentration in $\mathrm{H}_{2} \mathrm{O}$ (mg. $\mathrm{L}^{-1}$ ) and $\mathbf{2} \mathbf{S i O}_{2}$ (mg.g ${ }^{-1}$ ) respectively. $\mathrm{Q}_{\max }$ is the maximum MB that can be adsorbed on a monolayer ( $\mathrm{mg}$. $\left.\mathrm{g}^{-1}\right)$. Similarly, $K_{f}\left(\mathrm{mg}_{\mathrm{g}} \mathrm{g}^{-1}\right.$ ) and $n$ are constants in Freundlich model (Eq. (4)) for adsorption capacity and adsorption favorability respectively.

Langmuir model : $\frac{1}{q_{e}}=\frac{1}{Q_{\max } K_{L} C_{e}}+\frac{1}{Q_{\max }}$

$$
R_{L}=\frac{1}{1+K_{L} C_{0}}
$$

Freundlich model : $\log q_{e}=\log K_{F}+\frac{1}{n} \log C_{e}$

From correlation coefficients $\left(\mathrm{R}^{2}\right.$, Table 3$)$ it is clear that both Langmuir (Fig. 8f) and Freundlich model (Fig. 8g) provides a good fit with the experimental data. However, higher accuracy in Langmuir model describes better the absorption of MB. Based on Langmuir model, the maximum MB adsorption capacity of $\mathbf{2 S i O}_{\mathbf{2}}\left(Q_{\max }\right)$ was calculated to be $\sim 380 \mathrm{mg} \cdot \mathrm{g}^{-1}$. $R_{L}$ value derived by Eq. (3) signifies, if the isotherm is favorable $\left(0<R_{L}<1\right)$, linear $\left(R_{L}=1\right)$, irreversible $\left(R_{L}=0\right)$ or unfavorable $\left(R_{L}>1\right)[53,59]$. In this work, $R_{L}=0.95$ indicates favorable adsorption of MB. Heterogeneity factor $(n)$, calculated from Freundlich model shows if the adsorption follows a linear $(n=1)$, chemical $(n<1)$ or physical ( $n>1$ ) process. The value of $n=2.5$ shows some degree of physical adsorption of MB (Fig. 8g, Table 3), and the value of $n$ also shows a favorable adsorption of $\mathrm{MB}$ by $\mathbf{2} \mathrm{SiO}_{2}$ [60].

\subsection{Regeneration and reuse of $2 \mathrm{SiO}_{2}$}

To validate the practical application potential of $\mathbf{2 S i O}_{2}$, MB release, and reusability was studied. $\sim 37.0 \mathrm{wt} \% \mathrm{MB}$ containing $\mathbf{2 S i O}_{\mathbf{2}}$ obtained after $2 \mathrm{~h}$ adsorption was used for the release study (Fig. 9a, Fig. S13). In neutral pH, equilibrium $\mathrm{MB}$ release of within $20 \%$ (after $6 \mathrm{~h}$ ) suggests the release of only physio-adsorbed $\mathrm{MB}$, which is in good agreement with the Freundlich isotherm model. Decreased solubility of $\mathrm{MB}$ and increase in the number of negatively charged sites in the $\mathbf{2 S i O}_{\mathbf{2}}$ at alkaline $\mathrm{pH}$ lowered the MB release to only 7\% (Fig. S14) [61,62]. On the contrary, at pH 4.5 nearly $96 \%$ MB was released within 2 h. It can be due to the increased solubility of $\mathrm{MB}$ and the formation of positively charged sites in $2 \mathrm{SiO}_{2}$ at this $\mathrm{pH}$ (Fig. S14) repels MB out of the NPs [61]. Competition between $\mathrm{H}$-ion and $\mathrm{MB}$ prevents further readsorption of $\mathrm{MB}$ into $\mathbf{2} \mathbf{S i \mathbf { O } _ { 2 }}$.

Complete desorption of $\mathrm{MB}$ at $\mathrm{pH} 4.5$ (within $2 \mathrm{~h}$ ) regenerated the $\mathbf{S i O}_{2}$ for subsequent reuse. $\zeta$-potential of $\mathbf{2 S i O}_{2}$ at different stages of the adsorption-desorption cycle also confirmed its regeneration (Fig. S15). Negative $\zeta$-potential of $\mathbf{2 S i O}_{\mathbf{2}}$ approached isoelectric point after the adsorption of $\mathrm{MB}$ at the anionic sites in $\mathbf{2} \mathbf{S i O}_{\mathbf{2}}$ [63]. After desorption of $\mathrm{MB}$, negatively charged sites were free and $\zeta$-potential was close to the pristine $\mathbf{2 S i O}_{2}$. Reusability of $\mathbf{2 S i O}_{2}$ was investigated using 10 adsorption-desorption cycles (Fig. 9b) showed only a marginal decrease in adsorption capacity ( $8 \%)$ after the tenth cycle. P-content of
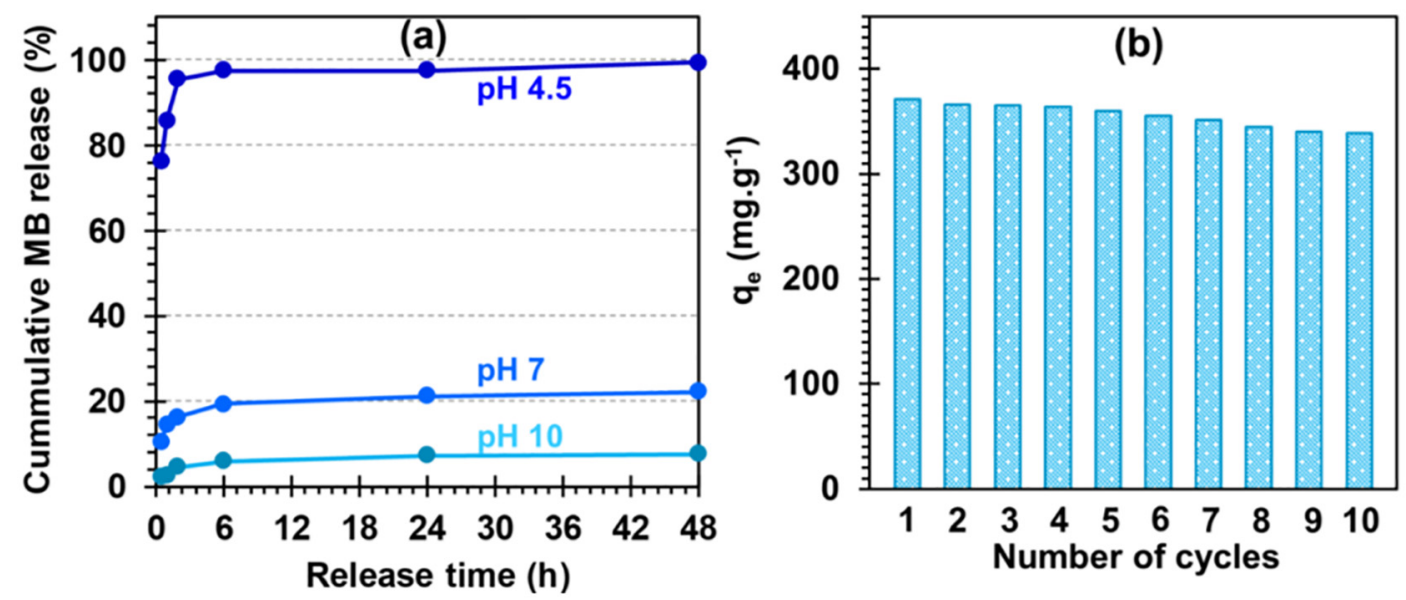

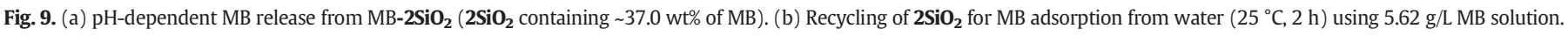

Table 4

MB absorption capacity ( $Q_{\max }$ ) of silica-based adsorbents determined by Langmuir model.

\begin{tabular}{|c|c|c|c|c|c|c|}
\hline Entry & Adsorbent & Surface area $\left(\mathrm{m}^{2} \cdot \mathrm{g}^{-1}\right)$ & Pore size $(\mathrm{nm})$ & Pore vol. $\left(\mathrm{cm}^{3} \cdot \mathrm{g}^{-1}\right)$ & $\mathrm{Q}_{\max }\left(\mathrm{mg} \mathrm{g}^{-1}\right)$ & Ref. \\
\hline 1 & MSN & 584.9 & 1.68 & 1.17 & 34.2 & {$[64]$} \\
\hline 2 & MSN composite & 598.0 & 3.4 & 1.06 & 62.8 & [65] \\
\hline 3 & Porous $\mathrm{SiO}_{2} \mathrm{NP}$ coated nano-web & 400.5 & - & 0.35 & 103.1 & [66] \\
\hline 4 & MSN from diatomite & 1288.0 & 2.8 & - & 347.2 & {$[54]$} \\
\hline 5 & $\mathrm{PO}(\mathrm{OH})_{2}$ functionalized periodic silica & 748.0 & 3.0 & 0.51 & 518.0 & [67] \\
\hline 6 & Cobalt impregnated silica NP & 378.2 & 3.0 & - & 250 & [68] \\
\hline 7 & Polymer functionalized $\mathrm{Fe}_{3} \mathrm{O}_{4} @ \mathrm{SiO}_{2} \mathrm{NP}$ & - & - & - & 421.9 & [69] \\
\hline 8 & Polyacrylic acrylamide grafted MSN & - & - & - & 375.9 & [70] \\
\hline 9 & Hybrid MSNP & 501.0 & 6.5 & 0.75 & 380.0 & This work \\
\hline
\end{tabular}


$\mathbf{2} \mathbf{S i O}_{\mathbf{2}}$ after the tenth cycle $(\sim 0.7 \%)$ was similar to the pristine $\mathbf{2} \mathbf{S i O} \mathbf{}_{\mathbf{2}}$ ( $\sim 0.8 \%)$, which minimizes the risk of secondary pollution due to ED release.

The MB adsorption capacity $\left(Q_{\max }\right)$ of the novel MSNP $\left(\mathbf{2 S i O}_{\mathbf{2}}\right)$ was compared with the recently reported silica-based adsorbents (Table 4). The $Q_{\max }$ of MSNPs (entry 9 ) was found to be superior to most of the listed adsorbents, except for entry 5 and 7 . In these two cases, the adsorption experiments were carried out in an alkaline medium ( $\mathrm{pH} \mathrm{9)}$ and as discussed earlier, alkaline medium favors adsorption of MB [61]. From the adsorption isotherm data, it can be said that $Q_{\max }$ of $\mathbf{2} \mathbf{S i O}_{\mathbf{2}}$ is comparable to the adsorbents listed in entry 5 and 7. Based on the preparation method and adsorption capacity, we can conclude that $\mathbf{2} \mathbf{S i O}_{2}$ is more potent than recently reported silica adsorbents.

\section{Conclusion}

In summary, a single-step and template-free synthesis method has been developed for the preparation of phosphonic acid-functionalized mesostructured silica nanoparticles with high surface area $\left(501 \mathrm{~m}^{2}\right.$. $\mathrm{g}^{-1}, \mathbf{2 i O}_{\mathbf{2}}$ ) using a nonsilane precursor. Elimination of template removal and post functionalization steps simplified the process, protected the surface functionalities, and reduced the processing time to $2 \mathrm{~h}$, otherwise difficult in state of art template-directed methods. NMR and FT-IR analysis confirmed the presence of - $\mathrm{SiOH}$ and $-\mathrm{PO}(\mathrm{OH})_{2}$ functionalities in on MSNPs. Unlike, SBA-15 and MCM-41 type material, randomly oriented pores with uniform pore width were formed within synthesized MSNPs. With the help of physical and chemical analysis, the mechanism of MSNP formation was postulated. The synergy of high porosity and functionality achieved high MB adsorption capacity (380 mg. ${ }^{-1}$ ) with excellent reusability of MSNPs (up to 10 recycling), which demonstrates its practical application potential in the field of pollution control. This novel MSNP can also be an ideal candidate for drug delivery and flame retardant applications. Additionally, the successful synthesis of MSNP using a nonsilane molecule broadens the precursor selection. Therefore, research is underway using different multifunctional nonsilane molecules at different synthesis conditions to improve the porosity and yield.

\section{Author contribution}

Dambarudhar Parida: Conceptualization; Methodology; Investigation; Data curation; Formal analysis; Supervision; Validation; Visualization; Writing - original draft; Writing - review \& editing.

Khalifah A. Salmeia: Investigation; Formal analysis; Writing - review \& editing.

Amin Sadeghpour: Investigation; Formal analysis; Software; Writing - review \& editing.

Shanyu Zhao: Investigation; Formal analysis; Writing - review \& editing.

Anjani K. Maurya: Investigation; Software; Formal analysis.

Khaleel I. Assaf: Investigation; Software; Formal analysis.

Eva Moreau: Investigation.

Sandro Lehner: Investigation.

Milijana Jovic: Investigation.

Hirsch Cordula: Investigation; Formal analysis; Writing - review \& editing.

Sabyasachi Gaan: Visualization; Investigation; Methodology; Project administration; Resources; Supervision; Writing - review \& editing.

\section{Declaration of Competing Interest}

The authors declare that they have no known competing financial interests or personal relationships that could have appeared to influence the work reported in this paper.

\section{Acknowledgements}

Authors thank Ms. Gabriela Kopeć for initial experiments. We are thankful to Dr. Daniel Rentsch for NMR analysis and Dr. Jean-Pierre Kaiser for performing the cytotoxicity experiments. The NMR hardware was partially granted by the Swiss National Science Foundation (SNSF, grant no. 206021_150638/1).

\section{Appendix A. Supplementary data}

Supplementary data to this article can be found online at https://doi. org/10.1016/j.matdes.2021.109494.

\section{References}

[1] F. Bibi, M. Ajmal, F. Naseer, Z.H. Farooqi, M. Siddiq, Preparation of magnetic microgels for catalytic reduction of 4-nitrophenol and removal of methylene blue from aqueous medium, Int. J. Environ. Sci. Technol. 15 (2018) 863-874.

[2] S.A. Jadhav, H.B. Garud, A.H. Patil, G.D. Patil, C.R. Patil, T.D. Dongale, P.S. Patil, Recent advancements in silica nanoparticles based technologies for removal of dyes from water, Colloids Interface Sci. Commun. 30 (2019) 100181.

[3] Y. Li, S.-j. Liu, F.-m. Chen, J.-e. Zuo, High-strength apatite/attapulgite/alginate composite hydrogel for effective adsorption of methylene blue from aqueous solution, J. Chem. Eng. Data 64 (2019) 5469-5477.

[4] Y. Wang, W. Wang, A. Wang, Efficient adsorption of methylene blue on an alginatebased nanocomposite hydrogel enhanced by organo-illite/smectite clay, Chem. Eng. J. 228 (2013) 132-139.

[5] E. Santoso, R. Ediati, Y. Kusumawati, H. Bahruji, D.O. Sulistiono, D. Prasetyoko, Review on recent advances of carbon based adsorbent for methylene blue removal from waste water, Mater. Today Chem. 16 (2020) 100233.

[6] J.H. Kim, B.J. Cha, Y.D. Kim, H.O. Seo, Kinetics and thermodynamics of methylene blue adsorption on the Fe-oxide nanoparticles embedded in the mesoporous $\mathrm{SiO} 2$, Adv. Powder Technol. 31 (2020) 816-826.

[7] R. Nicola, S.-G. Muntean, M.-A. Nistor, A.-M. Putz, L. Almásy, L. Săcărescu, Highly efficient and fast removal of colored pollutants from single and binary systems, using magnetic mesoporous silica, Chemosphere 261 (2020) 127737.

[8] M. KarzarJeddi, O. Laitinen, M. Mahkam, H. Liimatainen, Zwitterionic hybrid aerobeads of binary metal organic frameworks and cellulose nanofibers for removal anionic pollutants, Mater. Des. 196 (2020) 109106.

[9] B. Yu, Z. Li, H. Cong, G. Li, Q. Peng, C. Yang, Synthesis and application of sulfonated polystyrene/ferrosoferric oxide/diazoresin nanocomposite microspheres for highly selective removal of dyes, Mater. Des. 135 (2017) 333-342.

[10] T. Ataei-Germi, A. Nematollahzadeh, Bimodal porous silica microspheres decorated with polydopamine nano-particles for the adsorption of methylene blue in fixedbed columns, J. Colloid Interface Sci. 470 (2016) 172-182.

[11] M.K. Uddin, A. Nasar, Walnut shell powder as a low-cost adsorbent for methylene blue dye: isotherm, kinetics, thermodynamic, desorption and response surface methodology examinations, Sci. Rep. 10 (2020) 7983.

[12] O.S. Bayomie, H. Kandeel, T. Shoeib, H. Yang, N. Youssef, M.M.H. El-Sayed, Novel approach for effective removal of methylene blue dye from water using fava bean peel waste, Sci. Rep. 10 (2020) 7824.

[13] S.S. Park, M.H. Jung, Y.-S. Lee, J.-H. Bae, S.-H. Kim, C.-S. Ha, Functionalised mesoporous silica nanoparticles with excellent cytotoxicity against various cancer cells for pH-responsive and controlled drug delivery, Mater. Des. 184 (2019) 108187.

[14] J. Li, Z. Ding, Y. Li, J. Miao, W. Wang, K. Nundlall, S. Chen, Reactive oxygen speciessensitive thioketal-linked mesoporous silica nanoparticles as drug carrier for effective antibacterial activity, Mater. Des. 195 (2020) 109021.

[15] S. Jafari, H. Derakhshankhah, L. Alaei, A. Fattahi, B.S. Varnamkhasti, A.A. Saboury, Mesoporous silica nanoparticles for therapeutic/diagnostic applications, Biomed. Pharmacother. 109 (2019) 1100-1111.

[16] S. Saroj, S.J. Rajput, Composite smart mesoporous silica nanoparticles as promising therapeutic and diagnostic candidates: recent trends and applications, J. Drug Deliv. Sci. Technol. 44 (2018) 349-365.

[17] Y. Wu, Y. Zhang, J. Zhou, D. Gu, Recent progress on functional mesoporous materials as catalysts in organic synthesis, Emerg. Mater. 3 (2020) 247-266.

[18] S.D. Yambem, J. Timm, M. Weiss, A.K. Pandey, R. Marschall, Sulfonated mesoporous silica as proton exchanging layer in solid-state organic transistor, Adv. Electron. Mater. 3 (2017) 1700316.

[19] F. Sannino, A. Costantini, F. Ruffo, A. Aronne, V. Venezia, V. Califano, Covalent immobilization of $\beta$-glucosidase into mesoporous silica nanoparticles from anhydrous acetone enhances its catalytic performance, Nanomaterials (Basel) 10 (2020).

[20] F. Albertini, T. Ribeiro, S. Alves, C. Baleizão, J.P.S. Farinha, Boron-chelating membranes based in hybrid mesoporous silica nanoparticles for water purification, Mater. Des. 141 (2018) 407-413.

[21] K. Stawicka, M. Ziolek, Chapter 2 - silica hosts for acid and basic organosilanes: Preparation, characterization, and application in catalysis, in: A. Douhal, M. Anpo (Eds.), Chemistry of Silica and Zeolite-Based Materials, Elsevier 2019, pp. 27-56.

[22] C. Gunathilake, M.S. Kadanapitiye, O. Dudarko, S.D. Huang, M. Jaroniec, Adsorption of lead ions from aqueous phase on mesoporous silica with P-containing pendant groups, ACS Appl. Mater. Interfaces 7 (2015) 23144-23152.

[23] O.A. Dudarko, C. Gunathilake, V.V. Sliesarenko, Y.L. Zub, M. Jaroniec, Microwaveassisted and conventional hydrothermal synthesis of ordered mesoporous silicas 
with P-containing functionalities, Colloids Surf. A Physicochem. Eng. Asp. 459 (2014) 4-10.

[24] A.M. Basso, B.P. Nicola, K. Bernardo-Gusmão, S.B.C. Pergher, Tunable effect of the calcination of the silanol groups of KIT-6 and SBA-15 mesoporous materials, Appl. Sci. 10 (2020) 16

[25] M. Barczak, Template removal from mesoporous silicas using different methods as a tool for adjusting their properties, New J. Chem. 42 (2018) 4182-4191.

[26] L. Huang, C. Poh, S.C. Ng, K. Hidajat, S. Kawi, Preparation of supported mesoporous thin films concerning template removal by supercritical fluid extraction, Langmuir 21 (2005) 1171-1174.

[27] C.-S. Ha, S.S. Park, Periodic Mesoporous Organosilicas, 1 ed. Springer Singapore, Singapore, 2019.

[28] B. Du, Z. Cao, Z. Li, A. Mei, X. Zhang, J. Nie, J. Xu, Z. Fan, One-pot preparation of hollow silica spheres by using thermosensitive poly( $\mathrm{N}$-isopropylacrylamide) as a reversible template, Langmuir 25 (2009) 12367-12373.

[29] D.V. Quang, A. Dindi, K. Al-Ali, M.R.M. Abu-Zahra, Template-free amine-bridged silsesquioxane with dangling amino groups and its $\mathrm{CO} 2$ adsorption performance, J. Mater. Chem. A 6 (2018) 23690-23702.

[30] K.A. Salmeia, A. Neels, D. Parida, S. Lehner, D. Rentsch, S. Gaan, Insight into the synthesis and characterization of organophosphorus-based bridged triazine compounds, Molecules 24 (2019).

[31] J. Zeng, B. He, K. Lamb, R. De Marco, P.K. Shen, S.P. Jiang, Anhydrous phosphoric acid functionalized sintered mesoporous silica nanocomposite proton exchange membranes for fuel cells, ACS Appl. Mater. Interfaces 5 (2013) 11240-11248.

[32] S.P. Jiang, Functionalized mesoporous structured inorganic materials as high temperature proton exchange membranes for fuel cells, J. Mater. Chem. A 2 (2014) 7637-7655.

[33] M. Liu, S. Chen, X. Zhao, Y. Ye, J. Li, Q. Zhu, B. Zhao, W. Zhao, X. Huang, J. Shen, Biocompatible phosphonic acid-functionalized silica nanoparticles for sensitive detection of hypoxanthine in real samples, Talanta 117 (2013) 536-542.

[34] J. Courtat, F. Melis, J.-M. Taulemesse, V. Bounor-Legare, R. Sonnier, L. Ferry, P. Cassagnau, Effect of phosphorous-modified silica on the flame retardancy of polypropylene based nanocomposites, Polym. Degrad. Stab. 119 (2015) 260-274.

[35] A. Bifulco, D. Parida, K.A. Salmeia, R. Nazir, S. Lehner, R. Stämpfli, H. Markus, G. Malucelli, F. Branda, S. Gaan, Fire and mechanical properties of DGEBA-based epoxy resin cured with a cycloaliphatic hardener: combined action of silica, melamine and DOPO-derivative, Mater. Des. 193 (2020) 108862.

[36] A. Bifulco, D. Parida, K.A. Salmeia, S. Lehner, R. Stämpfli, H. Markus, G. Malucelli, F. Branda, S. Gaan, Improving flame retardancy of in-situ silica-epoxy nanocomposites cured with aliphatic hardener: combined effect of DOPO-based flame-retardant and melamine, Compos. Part C: Open Access 2 (2020) 100022.

[37] S. Bhakta, C.K. Dixit, I. Bist, K.A. Jalil, S.L. Suib, J.F. Rusling, Sodium hydroxide catalyzed monodispersed high surface area silica nanoparticles, Mater. Res. Expr. 3 (2016) 8.

[38] C.K. Dixit, S. Bhakta, A. Kumar, S.L. Suib, J.F. Rusling, Fast nucleation for silica nanoparticle synthesis using a sol-gel method, Nanoscale 8 (2016) 19662-19667.

[39] S. Brunauer, P.H. Emmett, E. Teller, Adsorption of gases in multimolecular layers, J. Am. Chem. Soc. 60 (1938) 309-319.

[40] E.P. Barrett, L.G. Joyner, P.P. Halenda, The determination of pore volume and area distributions in porous substances. I. Computations from nitrogen isotherms, J. Am. Chem. Soc. 73 (1951) 373-380.

[41] I. Langmuir, The constitution and fundamental properties of solids and liquids. II. Liquids.1, J. Am. Chem. Soc. 39 (1917) 1848-1906.

[42] H.M.F. Freundlich, Over the adsorption in solution, J. Phys. Chem. 57 (1906) 87.

[43] Y.-L. Wang, L. Zhu, B.-L. Guo, S.-W. Chen, W.-S. Wu, Mesoporous silica SBA-15 functionalized with phosphonate derivatives for uranium uptake, New J. Chem. 38 (2014) 3853-3861.

[44] Y.-C. Pan, H.-H. Gavin Tsai, J.-C. Jiang, C.-C. Kao, T.-L. Sung, P.-J. Chiu, D. Saikia, J.-H. Chang, H.-M. Kao, Probing the nature and local structure of phosphonic acid groups functionalized in mesoporous silica SBA-15, J. Phys. Chem. C 116 (2012) 1658-1669.

[45] P.W. Schmidt, Interpretation of small-angle scattering curves proportional to a negative power of the scattering vector, J. Appl. Crystallogr. 15 (1982) 567-569.

[46] J. Luo, G. Panzarasa, A. Osypova, F. Sorin, F. Spano, R.M. Rossi, A. Sadeghpour, L.F. Boesel, Polyphenols as morphogenetic agents for the controlled synthesis of mesoporous silica nanoparticles, Chem. Mater. 31 (2019) 3192-3200.

[47] C. Fernández-Lorenzo, L. Esquivias, P. Barboux, J. Maquet, F. Taulelle, Sol-gel synthesis of $\mathrm{SiO}_{2}-\mathrm{P}_{2} \mathrm{O}_{5}$ glasses, J. Non-Cryst. Solids 176 (1994) 189-199.

[48] Y. He, B. Zeng, S. Liang, M. Long, H. Xu, Synthesis of pH-responsive biodegradable mesoporous silica-calcium phosphate hybrid nanoparticles as a high potential drug carrier, ACS Appl. Mater. Interfaces 9 (2017) 44402-44409.
[49] O.A. Dudarko, C. Gunathilake, N.P. Wickramaratne, V.V. Sliesarenko, Y.L. Zub, J. Górka, S. Dai, M. Jaroniec, Synthesis of mesoporous silica-tethered phosphonic acid sorbents for uranium species from aqueous solutions, Colloids Surf. A Physicochem. Eng. Asp. 482 (2015) 1-8.

[50] H. Sarafraz, A. Minuchehr, G. Alahyarizadeh, Z. Rahimi, Synthesis of enhanced phosphonic functional groups mesoporous silica for uranium selective adsorption from aqueous solutions, Sci. Rep. 7 (2017) 11675.

[51] J. Gao, H. Lei, Z. Han, Q. Shi, Y. Chen, Y. Jiang, Dopamine functionalized tannic-acidtemplated mesoporous silica nanoparticles as a new sorbent for the efficient removal of Cu2 + from aqueous solution, Sci. Rep. 7 (2017) 45215.

[52] N.T. Vo, A.K. Patra, D. Kim, Reductant-free synthesis of silver nanoparticles by functionalized hollow doughnut mesoporous silica nanoparticles for preparation of catalytic nanoreactor, ChemistrySelect 3 (2018) 1772-1780.

[53] A.H. Karim, A.A. Jalil, S. Triwahyono, S.M. Sidik, N.H.N. Kamarudin, R. Jusoh, N.W.C. Jusoh, B.H. Hameed, Amino modified mesostructured silica nanoparticles for efficient adsorption of methylene blue, J. Colloid Interface Sci. 386 (2012) 307-314.

[54] Z.-H. Yu, S.-R. Zhai, H. Guo, T.-M. Lv, Y. Song, F. Zhang, H.-C. Ma, Removal of methylene blue over low-cost mesoporous silica nanoparticles prepared with naturally occurring diatomite, J. Sol-Gel Sci. Technol. 88 (2018) 541-550.

[55] S.K. Davidowski, G.P. Holland, Solid-state NMR characterization of mixed phosphonic acid ligand binding and organization on silica nanoparticles, Langmuir 32 (2016) 3253-3261.

[56] C. Coelho, F. Babonneau, T. Azaïs, L. Bonhomme-Coury, J. Maquet, G. Laurent, C. Bonhomme, Chemical bonding in silicophosphate gels: contribution of dipolar and J-derived solid state NMR techniques, J. Sol-Gel Sci. Technol. 40 (2006) 181-189.

[57] S.P. Szu, L.C. Klein, M. Greenblatt, Effect of precursors on the structure of phosphosilicate gels: 29Si and 31P MAS-NMR study, J. Non-Cryst. Solids 143 (1992) 21-30.

[58] P.D. Bahanur Becit, Dirk Zahn, Molecular mechanisms of mesoporous silica formation from colloid solution: ripening-reactions arrest hollow network structures, PLoS One 14 (2019) 11.

[59] H. Zhang, X. Li, G. He, J. Zhan, D. Liu, Preparation of magnetic composite hollow microsphere and its adsorption capacity for basic dyes, Ind. Eng. Chem. Res. 52 (2013) 16902-16910.

[60] W. Zeng, Y.-g. Liu, X.-j. Hu, S.-b. Liu, G.-m. Zeng, B.-h. Zheng, L.-h. Jiang, F.-y. Guo, Y. Ding, Y. Xu, Decontamination of methylene blue from aqueous solution by magnetic chitosan lignosulfonate grafted with graphene oxide: effects of environmental conditions and surfactant, RSC Adv. 6 (2016) 19298-19307.

[61] J. Zhang, B. Li, W. Yang, J. Liu, Synthesis of magnetic Fe304@hierarchical hollow silica nanospheres for efficient removal of methylene blue from aqueous solutions, Ind. Eng. Chem. Res. 53 (2014) 10629-10636.

[62] H.G. Ozcelik, M. Barisik, Electric charge of nanopatterned silica surfaces, Phys. Chem. Chem. Phys. 21 (2019) 7576-7587.

[63] S. Munkaila, J. Bentley, K. Schimmel, T. Ahamad, S.M. Alshehri, B.P. Bastakoti, Polymer directed synthesis of $\mathrm{NiO}$ nanoflowers to remove pollutant from wastewater, J. Mol. Liq. 114676 (2020).

[64] P. Qin, Y. Yang, X. Zhang, J. Niu, H. Yang, S. Tian, J. Zhu, M. Lu, Highly efficient, rapid, and simultaneous removal of cationic dyes from aqueous solution using monodispersed mesoporous silica nanoparticles as the adsorbent, Nanomaterials (Basel) 8 (2017).

[65] M. Abboud, T. Sahlabji, M.A. Haija, A.A. El-Zahhar, S. Bondock, I. Ismail, S.M.A.S. Keshk, Synthesis and characterization of lignosulfonate/amino-functionalized SBA15 nanocomposites for the adsorption of methylene blue from wastewater, New J. Chem. 44 (2020) 2291-2302.

[66] Z. Li, X. Tang, K. Liu, J. Huang, Q. Peng, M. Ao, Z. Huang, Fabrication of novel sandwich nanocomposite as an efficient and regenerable adsorbent for methylene blue and $\mathrm{Pb}$ (II) ion removal, J. Environ. Manag. 218 (2018) 363-373.

[67] J.R. Deka, C.-L. Liu, T.-H. Wang, W.-C. Chang, H.-M. Kao, Synthesis of highly phosphonic acid functionalized benzene-bridged periodic mesoporous organosilicas for use as efficient dye adsorbents, J. Hazard. Mater. 278 (2014) 539-550.

[68] N. Shukla, V. Gupta, D.K. Pal, A.S. Rawat, A. Saxena, S. Shrivastava, P.K. Rai, Zero valent cobalt impregnated silica nanoparticles for the sanitation of contaminated water, Environ. Prog. Sustain. Energy 38 (2019) S42-S53.

[69] X. Zheng, H. Zheng, R. Zhao, Y. Sun, O. Sun, S. Zhang, Y. Liu, Polymer-functionalized magnetic nanoparticles: synthesis, characterization, and methylene blue adsorption, Materials 11 (2018) 1312.

[70] T.A. Saleh, S.H. Al-Ruwayshid, A. Sarı, M. Tuzen, Synthesis of silica nanoparticles grafted with copolymer of acrylic acrylamide for ultra-removal of methylene blue from aquatic solutions, Eur. Polym. J. 130 (2020) 109698. 